\title{
O monitoramento de concorrentes na pequena empresa: um estudo de caso em empresa catarinense
}

\author{
Éverton Luís Pellizzaro de Lorenzi Cancellier \\ Doutor em Administração pela Universidade de São Paulo \\ Professor Adjunto da Universidade do Estado de Santa \\ Catarina/UDESC \\ Docente permanente do Mestrado Acadêmico em \\ Administração e do Mestrado Profissional em Administração \\ da UDESC \\ everton.cancellier@udesc.br
}

Contextus

\section{RESUMO:}

Entre os inúmeros fatores e variáveis que compõem o ambiente externo, os concorrentes figuram como força relevante para a compreensão da situação competitiva das empresas. Os pequenos negócios, embora tenham menor disponibilidade de recursos financeiros, humanos e tecnológicos em relação às grandes empresas, precisam empreender a atividade de monitoramento dos concorrentes e encontrar alternativas que viabilizem sua realização. Nesse contexto, o presente estudo tem por objetivo analisar o processo de monitoramento de concorrentes em uma empresa de pequeno porte, e, para isso, lançou-se mão do método de estudo de caso. Os resultados corroboram outros estudos na área e indicaram que a pequena empresa investigada monitora os concorrentes com pouca ênfase e o faz por meio de fontes pessoais externas à organização.

Palavras-chave: Monitoramento. Ambiente externo. Concorrentes. Pequena empresa.

\section{ABSTRACT:}

Among the number of factors and variables that compose the external environment, the competitors appear as relevant power for the understanding of the competitive situation of the companies. Although having less availability of financial, human and technological resources concerning the big companies, the small businesses need to undertake the competitors' monitoring activity and find alternatives to enable achievement. In this context, the present study aims at analyzing the competitors'monitoring process in a small company, and for its achievement the method of case study was used. The results have corroborated other investigations in the area and have indicated that the company investigated monitors the competitors with little emphasis and it does so through personal external sources to the organization.

Keywords: Scanning. External environment. Competitors. Small business. 


\section{INTRODUÇÃO}

A crescente competitividade dos mercados é uma das principais fontes de preocupação das empresas atualmente. As constantes e profundas transformações que caracterizam os ambientes de negócio têm forçado os administradores a empreenderem grandes esforços no sentido de acompanhar, interpretar e compreender a natureza dessas mudanças e as suas implicações para as organizações. Stewart, May e Kalia (2008) expõem que as mudanças no ambiente de negócios, particularmente aquelas associadas com as transições das economias ditas emergentes, desafiam os empreendimentos a se adaptar a contextos em que as forças de mercado criam novas exigências competitivas, demandando transformação nas capacidades organizacionais.

Esse amplo elenco de eventos e de tendências representa grande desafio para os dirigentes de empresas no intento de manterem-se atualizados e de, efetivamente, utilizarem as informações oriundas do ambiente externo em suas decisões. Para lidar com tal desafio, Haase e Franco (2011) argumentam que as empresas precisam ser capazes de adquirir, analisar e compreender as informações relacionadas ao estado atual e à evolução futura dos ambientes nos quais atuam, e indicam o monitoramento do ambiente como um método útil para a adaptação ao meio externo.

O monitoramento do ambiente, entendido como a forma pela qual os dirigentes obtêm informações relevantes sobre eventos que ocorrem fora da empresa de maneira a guiar futuros cursos de ação (AGUILAR, 1967), é atividade que oferece várias possibilidades às organizações. Entre os benefícios relatados em pesquisas sobre a adoção de práticas de monitoramento do ambiente externo, Kamoun-Chouk (2007) destacam os seguintes: o monitoramento permite reconhecer fatores externos que influenciam significativamente a direção da organização, colabora para o desenvolvimento de planos e estratégias, e contribui para o ajuste entre estratégia organizacional e demandas de mercado para o alcance de um desempenho superior.

Entre os fatores do ambiente que merecem atenção por parte dos gestores está a concorrência. Bergen e Peteraf (2002) destacam que a identificação e análise de competidores é uma tarefa chave para os gestores reforçarem suas defesas contra a incursão de concorrentes e para a elaboração de respostas competitivas. Ocorre que estudos na área mostram que as empresas de pequeno porte privilegiam fatores mercadológicos e efetuam um menor esforço de monitoramento em relação aos competidores (DAFT; SORMUNEN; PARKS, 1988; WALTERS, JIANG; KLEIN, 2003). Nesse sentido, Groom e David (2001) verificaram que os gestores de pequenas e médias empresas costumam pensar que conhecem seus mercados de atuação e, portanto, diminuem os esforços de monitoramento. No entanto, aqueles que menos se envolvem na busca de dados dos concorrentes formam o grupo mais insatisfeito e com menor desempenho organizacional.

Embora o monitoramento do ambiente venha recebendo grande atenção na literatura da área, muitos estudos continuam centrados em empresas de grande porte (McEWEN, 2008). Ocorre que para desenvolver e sustentar uma vantagem competitiva, o acesso a informações relevantes e tempestivas por meio do monitoramento é igualmente importante para as empresas menores (FRANCO et al.; 2011).

Stewart, May e Kalia (2008) argumentam que os resultados de estudos com gestores de grandes organizações não podem ser generalizados para os empreendedores em pequenas empresas, cujas cognições e respostas parecem ser distintas. Pequenas empresas se distinguem das grandes em aspectos que influenciam o esforço de monitoramento: as pequenas apresentam poucos recursos para pesquisas, baixa presença de sistemas estruturados de informação, limitados recursos financeiros e dependência de poucos indivíduos na gestão superior para as atividades estratégicas de monitoramento. Tais características reforçam a necessidade de estudar o fenômeno no âmbito de empresas de pequeno porte.

Nesse contexto, considerando que as pequenas empresas possuem dificuldades em analisar seu ambiente concorrencial e que a pesquisa sobre monitoramento ambiental na pequena empresa no Brasil é incipiente, 
este trabalho tem como objetivo analisar o processo de monitoramento de concorrentes na realidade da pequena empresa. Trata-se de um campo complexo que precisa ser melhor entendido não só no âmbito das práticas de monitoramento adotadas pela empresas em geral, mas também na realidade das empresas de pequeno porte.

\section{MONITORAMENTO DO AMBIENTE}

As organizações são sistemas abertos que necessitam de cuidadosa administração para satisfazer e equilibrar necessidades internas, assim como se adaptar a circunstâncias ambientais. Por isso, não se pode afirmar que existe uma forma única e correta de ajuste, e, sim, que a forma adequada depende do tipo de tarefa ou do ambiente dentro do qual se está lidando. Da mesma maneira, várias podem ser as percepções diante das informações externas, possibilitando variadas interpretações e tomadas de decisão (MORGAN, 1996).

Diferentes arranjos organizacionais são necessários para lidar com diferentes condições de mercado e de tecnologia. Organizações que operam em ambientes incertos e turbulentos precisam atingir um grau mais alto de diferenciação interna, ou seja, entre departamentos, do que aquelas que estão em ambientes menos complexos e mais estáveis (MORGAN, 1996). Tushman e Nadler (1997) afirmam que as organizações precisam dispor de suficiente diversidade interna de estratégias, estruturas, pessoas e processos para possibilitar a inovação e fomentar o aprendizado organizacional. Destacam que, para competir num ambiente altamente dinâmico, as empresas precisam criar novos produtos, serviços e processos, adotando a inovação como um modo de vida corporativo.

Para lidar com esse desafio do ambiente competitivo, as empresas precisam aprender sobre as variáveis externas que têm maior influência sobre os objetivos. Beal (2000) considera o monitoramento ambiental como o primeiro passo no processo de alcançar um adequado ajuste da estratégia da organização com o ambiente, uma vez que uma das principais vantagens de adotar práticas de monitoramento ambiental reside na possibilidade de conhecer oportunidades e ameaças que influem no desempenho e na sobrevivência organizacional, capacitando a empresa a formular estratégias competitivas congruentes com as condições ambientais enfrentadas.

Em seu trabalho seminal, Aguilar (1976) define o fenômeno como a busca de informações sobre eventos e relacionamentos no ambiente externo de uma empresa e a consequente geração do conhecimento que irá auxiliar os executivos principais na tarefa de definir a futura linha de ação da empresa. Existem vários conceitos associados ao de monitoramento ambiental, destacando-se, entre eles, os de inteligência competitiva, de inteligência empresarial e de inteligência de negócios. Enquanto o primeiro refere-se à analise dos concorrentes, os demais dizem respeito às condições competitivas em um contexto empresarial mais amplo, envolvendo o acompanhamento de forças políticas, econômicas e sociais que possam ser de interesse para a empresa (HOHHOF, 1994). O conceito de inteligência empresarial aproxima-se do de monitoramento ambiental e, em muitos contextos, são considerados equivalentes.

Já Choo (1999) explica que o monitoramento ambiental é complementar, mas distinto de atividades de recebimento de informações e destaca o papel da análise e interpretação dos dados como fundamental para a geração de conhecimento do ambiente externo.

De acordo com Daft e Weick (1984), a interpretação é o elemento crítico que distingue organizações humanas de sistemas menos complexos. Há muitas imagens de interpretações na literatura, incluindo monitoramento, compreensão, interpretação, entendimento e aprendizado (Duncan; Weiss, 1979; Hedlerg, 1981; Weick, 1973). Esses conceitos podem ser organizados em 3 estágios que constituem todo o processo: escaneamento, interpretação e aprendizagem.

A interpretação, segundo Daft e Weick (1984), é o processo por meio do qual os gerentes traduzem dados em conhecimento e entendimento sobre o meio ambiente. As organizações que ordenam os dados podem experimentar alta porcentagem de equívocos, e a tendência é diminuir de acordo com o andamento do processo. Geralmente, quanto maior a quantidade de equívocos nos dados menor o número de regras usadas para chegar à interpretação. 
O escaneamento está preocupado com a obtenção de dados. A interpretação é o processo de traduzir eventos e desenvolver entendimento e cenas conceituais entre os membros da alta escala organizacional. O último estágio, o de aprendizagem, distingue-se da interpretação pelo fato de conceber ação, e é conhecido como o processo no qual o conhecimento e as ações entre meio ambiente e organizações são desenvolvidos (DAFT; WEICK, 1984).

Com base em uma análise da literatura das áreas de monitoramento, gerenciamento de temas estratégicos e formulação e diagnóstico de questões estratégicas, Dutton, Walton e Abrahamson (1989) argumentam que os trabalhos sobre monitoramento focalizam o processo pelo qual os decisores identificam e acompanham eventos e tendências originários do ambiente externo. Segundo esses autores, embora também focalizando eventos do ambiente externo, o gerenciamento de questões estratégicas revela uma postura mais orientada para a ação, buscando explorar respostas concretas às questões em vez de limitar-se à analise do processo de detecção e avaliação das informações. Já a literatura sobre formulação e diagnóstico de questões estratégicas focaliza as etapas de reconhecimento, formulação e diagnóstico dos primeiros estímulos a ativarem o processo decisório. Essa última literatura, segundo Dutton, Walton e Abranhamson (1989), mantém interfaces com as disciplinas de comportamento organizacional, política empresarial, psicologia cognitiva e gerência de operações.

Essas três áreas de conhecimento-monitoração ambiental, gerenciamento de questões estratégicas e formulação e diagnóstico de questões estratégicas - revelam maneiras ao mesmo tempo distintas e complementares de analisar temas ou questões importantes para as organizações e, em conjunto, constituem um esquema referencial capaz de orientar estudos sobre as formas pelas quais o ambiente externo é analisado pelos decisores.

Segundo Choo (1999), o monitoramento de ambiente lança uma relação regular maior e analisa informações sobre cada setor do ambiente externo que pode ajudar a administração a planejar o futuro da organização. Monitorar abrange tanto aspectos do ambiente operacional - como clientes, competidores e fornecedores - quanto aspectos do macroambiente, por exemplo, tecnologia, condições econômicas, ambiente regulador, ambiente político, tendências demográficas e sociais.

O monitoramento do ambiente tem recebido atenção dos estudos na área e tem sido investigado em variados contextos - tais como organizações com e sem fins lucrativos, pequenas e médias empresas - e em diferentes indústrias. O Quadro 1, a seguir, mostra um levantamento dos estudos sobre o tema realizados nos últimos cinco anos.

\begin{tabular}{|c|c|c|}
\hline AUTOR(ES) & MÉTODO & ÊNFASE \\
\hline McEwen (2008) & Ensaio teórico & $\begin{array}{l}\text { Proposição de modelo de } \\
\text { monitoramento para aprendizagem em } \\
\text { novos empreendimentos }\end{array}$ \\
\hline $\begin{array}{l}\text { Stewart, May e Kalia } \\
\text { (2008) }\end{array}$ & $\begin{array}{l}\text { Survey com } \\
\text { empreendedores norte- } \\
\text { americanos e indianos }\end{array}$ & $\begin{array}{l}\text { Relação entre acesso a fontes de } \\
\text { informação e percepção da incerteza } \\
\text { ambiental }\end{array}$ \\
\hline $\begin{array}{l}\text { Muhammad, Jantan e } \\
\text { Taib (2009) }\end{array}$ & $\begin{array}{l}\text { Survey com gestores de } \\
\text { empresas de diversos portes } \\
\text { e indústrias }\end{array}$ & $\begin{array}{l}\text { Relação entre monitoramento do } \\
\text { ambiente e decisões estratégicas de } \\
\text { investimentos }\end{array}$ \\
\hline Franco et al. (2011) & $\begin{array}{l}\text { Survey com empresas } \\
\text { portuguesas }\end{array}$ & $\begin{array}{l}\text { Comparação de práticas de } \\
\text { monitoramento entre pequenas e } \\
\text { grandes empresas }\end{array}$ \\
\hline $\begin{array}{l}\text { Zhang, Majid e Foo } \\
\text { (2010) }\end{array}$ & Ensaio teórico & $\begin{array}{l}\text { Relação entre monitoramento do } \\
\text { ambiente, habilidades informacionais e } \\
\text { incerteza ambiental }\end{array}$ \\
\hline $\begin{array}{l}\text { Haase e Franco } \\
\text { (2011) }\end{array}$ & $\begin{array}{l}\text { Survey com empresas } \\
\text { portuguesas }\end{array}$ & $\begin{array}{l}\text { Efeito tamanho e indústria no uso de } \\
\text { fontes de informação para o } \\
\text { monitoramento }\end{array}$ \\
\hline Davis et al. (2011) & $\begin{array}{l}\text { Survey com } 126 \\
\text { empreendedores norte- } \\
\text { americanos de entidades } \\
\text { com e sem fins lucrativos }\end{array}$ & $\begin{array}{l}\text { Relação entre orientação } \\
\text { empreendedora, monitoramento do } \\
\text { ambiente e estratégia de marketing }\end{array}$ \\
\hline Chrusciel (2011) & $\begin{array}{l}\text { Estudo de caso em } \\
\text { instituição pública }\end{array}$ & $\begin{array}{l}\text { Monitoramento e decisão estratégica } \\
\text { em empresa de facilities management }\end{array}$ \\
\hline $\begin{array}{l}\text { Babatunde e Adebisi } \\
\text { (2012) }\end{array}$ & $\begin{array}{l}\text { Survey com gestores de } \\
\text { grandes empresas }\end{array}$ & $\begin{array}{l}\text { Relação entre monitoramento do } \\
\text { ambiente e desempenho } \\
\text { organizacional }\end{array}$ \\
\hline
\end{tabular}

Fonte: elaboração do autor (2013)

Essa variedade de contextos em se situam os estudos recentes mostra a relevância e amplitude que o tema tem recebido na literatura, estimulando novas pesquisas que possam expandir os resultados que vem sendo obtidos nesse campo de conhecimento.

\section{AMBIENTE ORGANIZACIONAL}

O ambiente organizacional tem sido classificado, entre outras maneiras, em interno e externo (DUNCAN, 1972) e geral e de tarefa (THOMPSON, 1976). Dill (1958) categoriza o ambiente de tarefa em setores relativos a clientes (distribuidores e usuários), fornecedores, concorrentes (por mercado e por recursos) e grupos regulamentadores (governo, sindicatos e associações 
interorganizacionais). Em outros importantes estudos na área de monitoramento (DAFT; SORMUNEN; PARKS, 1988; AUSTER; CHOO, 1999), o ambiente organizacional é subdividido nos seguintes setores ou segmentos: setor cliente; setor concorrência; setor tecnológico; setor regulatório; setor econômico; setor sociocultural.

Pode-se concluir, portanto, que a visão das organizações como entidades processadoras de informações (não apenas internas, mas também externas) é perspectiva importante para estudos empíricos sobre os processos pelos quais elas se adaptam a seus ambientes. Nesse processamento, torna-se importante reconhecer que o ambiente precisa ser percebido pelos gestores para ser interpretado. Assim, o ambiente resulta da interpretação subjetiva que os indivíduos dentro das organizações fazem sobre o ambiente real (BOURGEOIS III, 1980).

Características do ambiente têm fortes implicações em muitos aspectos da gestão organizacional, incluindo estratégia, estrutura, processos e resultados. Desse modo, conceber e avaliar o ambiente passa a ser fundamental e a avaliação do ambiente de tarefa, onde se localizam os concorrentes, assume papel de destaque (HARRIS, 2004).

O monitoramento do ambiente possibilita direcionar a ação gerencial no sentido de buscar o desenvolvimento de mecanismos de captação, sistematização, armazenamento e uso de informações que possam assegurar a sobrevivência e o desenvolvimento da organização em ambientes complexos e instáveis, e mostram-se relevantes para diferentes contextos organizacionais. Nesse sentido, Davis et al. (2011) apresentam resultados de práticas de monitoramento do ambiente externo em aspectos ligados aos competidores tanto em organizações com fins lucrativos como naquelas sem fins lucrativos. É preciso considerar que, segundo Choo (1999), os gerentes que percebem o ambiente como mais incerto tenderão a monitorar mais. Vários estudos verificaram que a incerteza percebida de ambiente é um bom prognosticador da quantia e da intensidade de monitorar. A incerteza percebida de ambiente é uma função da complexidade percebida e do dinamismo percebido do ambiente externo.

Galbraith (1986) introduziu a noção de que a incerteza presente no processo decisório pode ser definida operacionalmente como a diferença entre a informação necessária e a informação disponível para realizarse uma tarefa. De acordo com esse princípio, para que uma unidade organizacional alcance níveis adequados de eficiência, sua capacidade de processamento de informação precisa ser compatível com sua necessidade de informação, e isso dependerá, essencialmente, da natureza da organização e de seus mecanismos de coordenação e controle (TUSHMAN; NADLER, 1997).

\section{FONTES DE MONITORAMENTO}

A aquisição de informações envolve a seleção e o uso de fontes que podem ser classificadas em diferentes formas. Aguilar (1967) propôs uma classificação que tem sido seguida por inúmeros estudos na área, dividindo as fontes em internas e externas e em pessoais e impessoais. Auster e Choo (1993) e Choo (1999) explicam que as fontes internas são acessadas dentro da organização e podem ser pessoais, como empregados, ou impessoais, como relatórios gerenciais e documentos. As fontes externas podem ser subdivididas em pessoais e impessoais. Como exemplos de fontes externas pessoais estão clientes, concorrentes e funcionários de órgãos governamentais; exemplificando fontes impessoais, tem-se jornais, periódicos e associações comerciais e industriais, entre outras.

Como o monitoramento e os contatos com fontes aumentam o acesso da empresa a informações atuais sobre os contextos de mudança do ambiente de negócios, Beal (2000) argumenta que fazer uso de um amplo leque de tipos de fontes torna-se importante tanto para grandes quanto para pequenos negócios.

Sutton (1998), em sua pesquisa sobre práticas de inteligência empresarial em empresas norte-americanas, identificou uma lista de fontes assinaladas pelos administradores como importantes ou moderadamente importantes. Entre elas podem-se mencionar contatos diretos com o setor de negócios, informações publicadas e outras fontes, como analistas financeiros, anúncios, 
para citar algumas.

Embora os gerentes monitorem com um vasto leque de fontes, nas pequenas empresas eles preferem informações novas de fontes pessoais quando procuraram dados sobre setores ambientais baseados no mercado, que são altamente fluídos e ambíguos. Há alguma evidência para indicar que essa seleção de fontes para monitorar é influenciada pela qualidade percebida da fonte e não somente pela sua acessibilidade percebida (CHOO, 1999).

Auster e Choo (1993), em seus estudos com executivos dos setores de publicações e telecomunicações canadenses, concluíram que jornais e periódicos são as fontes mais utilizadas e que a frequência de uso se relaciona positivamente com a qualidade e a acessibilidade da fonte. Os mesmos autores observam que os gerentes preferem fontes pessoais de informação, consideradas mais ricas, como clientes, colegas e subordinados. Bibliotecas corporativas, centros de documentação e meios eletrônicos são pouco utilizados no processo de monitoração.

No contexto de pequenas empresas, devido à pouca presença de sistemas de informação formais, predomina o uso de fontes pessoais e informais (McEWEN, 2008). Estudos na área (SMELTZER; FANN; NIKOLAISEN, 1988; BEAL, 2000; HAASE; FRANCO, 2011) apontam um predomínio de acesso a fontes pessoais informais tais como consumidores, fornecedores, competidores e colegas nas empresas menores em relação às maiores de suas amostras.

\section{MONITORAMENTO DE CONCORRENTES NA PEQUENA EMPRESA}

A identificação de competidores é uma tarefa relevante para os gestores interessados em obter conhecimento sobre as condições de seu ambiente de negócios. Bergen e Peteraf (2002) oferecem uma abordagem para a identificação de concorrentes, subdividindo-os em: diretos, potenciais e indiretos. Essa divisão se baseia na avaliação da semelhança dos mercados atendidos e dos recursos possuídos.
Os concorrentes diretos se caracterizam por outras empresas que atendem as mesmas necessidades de clientes e dispõem dos mesmos tipos de recursos estratégicos, possuindo, assim, similaridade em termos de recursos internos e mercados de atuação. Concorrentes potenciais, ou entrantes, se caracterizam por outras empresas que dispõem dos mesmos tipos de recursos estratégicos, mas no momento não atendem as mesmas necessidades de clientes. No grupo de concorrentes indiretos, ou substitutos, estão as empresas que atendem as mesmas necessidades de clientes, mas não dispõem de recursos estratégicos semelhantes. As demais empresas do setor que atendem necessidades diversas de clientes e possuem recursos estratégicos de distinta natureza estão completamente fora do escopo competitivo no presente, embora essa condição possa mudar com o tempo, na medida em que as empresas alteram suas posições (BERGEN; PETERAF, 2002).

Na literatura em Administração, um dos principais fatores externos considerados influentes para a competitividade organizacional é a concorrência. Fann e Smeltzer (1989) investigaram o uso que pequenas empresas fazem de informações sobre concorrentes no planejamento de curto e de longo prazo. De forma geral, o estudo mostrou que as pequenas empresas não valorizam informações sobre a concorrência e consideram que se seu produto é bom será vendido, fazendo pouca diferença a postura dos competidores. O pouco apreço pelo papel dos concorrentes ocorreu independentemente do porte, da receita, da idade ou do setor de atuação das empresas pesquisadas. Os consumidores, fornecedores e as publicações do setor foram considerados fontes mais valorizadas do que os competidores. Outro fator de destaque foi que a busca de informações dos competidores não de se dá de forma direta, mas por meio de empregados, consumidores, fornecedores e propaganda, ou seja, indiretamente. A baixa interação com concorrentes refletiu também na inexistência de práticas cooperativas, como compras conjuntas.

A pouca preocupação com competidores por parte de pequenas empresas também recebeu suporte no estudo de Groom e David (2001). Os autores identificaram que a grande maioria dos pequenos negócios não se preocupa 
com informações sobre competidores, especialmente nas empresas consideradas de melhor performance. No entanto, algumas barreiras foram identificadas para o acesso a essas informações. A falta de processo formal para compartilhar informações foi considerada a principal barreira por metade das empresas pesquisadas, enquanto $36 \%$ citaram a falta de recursos e a inabilidade para lidar com informações em conjunto. No Brasil, resultados semelhantes indicando a pouca atenção para com competidores foram verificados nos estudos de Fidelis e Cendon (2002) e Menezes e Almeida (1997). De certa forma dissonante, estão os resultados da pesquisa de Daft et al. (1988). Os autores identificaram que os competidores passam a ser monitorados quando a empresa os percebe como geradores de incerteza e apresenta maior desempenho, e recebem pouca atenção quando a empresa apresenta menor desempenho.

A análise conjunta de todas essas pesquisas permite inferir algumas considerações importantes. A consciência da importância de se obter informações parece existir, uma vez que as pesquisas mostram que as pequenas empresas realizam com frequência atividades de monitoramento de informações do ambiente externo.

Os estudos indicam que as empresas de menor porte baseiam-se muito em fontes pessoais e informais, sem apresentar um sistema mais estruturado de coleta e análise de dados. Alguns fatores permanecem subvalorizados, especialmente a investigação sobre os concorrentes e o uso de fontes formais e escritas. Essas preferências podem dificultar que as informações obtidas por uma fonte sejam referendadas ou contestadas por outras fontes, aumentando o conhecimento do ambiente externo dentro da empresa.

De forma geral, os resultados sugerem que os sistemas de monitoramento não devem ser restritos a fornecer dados de forma contínua, privilegiando algumas fontes em detrimento de outras. O monitoramento deve contemplar múltiplas fontes, mantendo aberto o leque de opções, uma vez que a estratégia é incremental e reflete uma gradual aprendizagem por parte da organização sobre o meio ambiente.

\section{PROCEDIMENTOS METODOLÓGICOS}

Para a realização deste trabalho, utilizou-se a pesquisa qualitativa de acordo com as abordagens de Triviños (1987) e Godoy (1995), com base no delineamento de estudo de caso conforme Yin (2001).

A pesquisa qualitativa envolve a adoção de uma abordagem dedicada à análise do significado das ações de indivíduos, grupos ou organizações no meio ecológico e no contexto social em que são construídas, levando em conta os componentes da situação em suas interações e influências recíprocas, sem fazer generalizações estatísticas e relações lineares de causa e efeito (CHIZZOTTI, 1995; ALVES, 1991). A presente pesquisa apresenta uma natureza qualitativa, uma vez que estuda o fenômeno monitoramento de concorrentes em pequenas empresas no contexto de relações em que ele aparece.

Quanto aos objetivos, a pesquisa é do tipo exploratória (GIL, 1994), na medida em que se propõe a investigar e detalhar o processo de monitoramento de concorrentes na realidade de uma pequena empresa, tema pouco explorado na literatura brasileira.

As principais fontes de evidências para Yin (2001) são a documentação, os registros em arquivos, as entrevistas, a observação direta, a observação participante e os artefatos físicos. Nesta pesquisa, a técnica predominante de coleta de dados foi a entrevista semiestruturada realizada com o responsável pelo monitoramento de concorrentes da empresa e seu atual gestor. $\mathrm{O}$ entrevistado é o principal gestor do empreendimento desde 1980, quando do falecimento de seu pai e fundador do negócio, e responde por todas as decisões e análises de cunho estratégico e comercial, incluindo as relativas aos concorrentes.

Para o levantamento de dados, foram realizadas duas entrevistas com duração média de uma hora e trinta minutos cada uma; a primeira entrevista para resgatar o histórico e dados sobre a análise de concorrentes, e a segunda, para confirmar e checar a consistência dos dados obtidos por meio de relato sintético.

O roteiro das entrevistas foi subdividido em duas partes: uma parte de histórico e caracterização do negócio e outra 
de levantamento das práticas de análise dos concorrentes. A primeira parte continha questões sobre a fundação e os primeiros gestores e sobre os fatos mais marcantes da vida da empresa, como investimentos e mudanças significativas. A segunda parte abrangia questões que suscitavam a identificação e a caracterização dos concorrentes, os dados dos concorrentes que o gestor busca obter, as fontes de acesso a esses dados e o eventual tratamento ou uso dessas informações.

Para viabilizar a análise, todo o conteúdo das entrevistas realizadas foi transcrito e organizado de forma a descrever o processo de monitoramento dos concorrentes da empresa. Utilizando as abordagens de monitoramento do ambiente de Aguilar (1967) e Choo (1999) que envolvem a busca de informações externas, fontes, registro e interpretação dessas informações, a análise foi realizada agrupando os dados obtidos nas seguintes categorias analíticas: identificação dos concorrentes, tipo de informação obtida dos concorrentes, fontes acessadas e armazenamento das informações obtidas. Por solicitação da empresa, seu nome foi preservado em sigilo, de modo que se utiliza aqui o termo "Empresa A" para designá-la.

\section{RESULTADOS}

A Empresa A foi fundada na década de 1960 quando seu proprietário, ao se aposentar, comprou um prelo manual, uma guilhotina e algumas fontes de tipos. A primeira instalação foi na sala da própria casa, em Florianópolis. Naquela época, a cidade contava com pouco mais de 100.000 habitantes, um comércio fraco e poucas empresas de serviços e indústria. A Empresa A foi a quarta do ramo em toda a região, que nessa época não dispunha de gráficas no sistema de off-set, nas quais se podem reproduzir impressos em quadricromia, com fotos e imagens multicoloridas. À época, formulários simples eram montados em uma chapa de chumbo, onde o tipógrafo compunha letra por letra até formar o que o cliente necessitava.

Em meados de 1975, a empresa comprou um galpão nas proximidades da primeira instalação, e a antiga casa ficou somente servindo de escritório para receber clientes. O crescimento foi tal que nessa época a empresa já contava com quinze funcionários e impressoras automatizadas. Em 1978, a empresa comprou sua primeira off-set. Esse equipamento já representava uma grande evolução, pois dispensava todo o trabalho manual para a montagem de chapas.

Em 1980, com o falecimento do fundador, o filho mais novo e sua esposa passaram a dirigir a organização. Nesse período, a gráfica mudou suas instalações para São José, município vizinho de Florianópolis, onde passou por momentos de forte crescimento, chegando a ter mais de cinquenta funcionários. Por volta de 1995, foi adquirida a primeira impressora bicolor da região, o que representou uma mudança em termos de produção e qualidade final de impressão em relação à concorrência. Atualmente, a Empresa A trabalha para pequenas e médias empresas da região de Florianópolis, para prefeituras e para o governo do estado.

A gráfica, nesses 30 anos de atividades, passou por grandes mudanças e transformações. Em 1966, quando iniciou suas atividades, a empresa possuía somente equipamentos tipográficos que permitiam imprimir não mais que pedidos pequenos e sem muita qualidade. Com a compra de equipamentos mais sofisticados, ela passou a atender clientes maiores e agências de publicidade. Nessa mesma época houve também alteração de endereço, o que fez mudar sua clientela habitual, por ser muito longe dos eventuais compradores, e a gráfica adotou uma estratégia de captação de clientes por intermédio de vendedores externos.

O atual diretor comercial e sócio proprietário da Empresa A se afastou por quatro anos da organização, pois recebeu um convite do governo do estado para trabalhar como diretor de uma empresa estatal. Nesse período, a empresa praticamente faliu. Foram alguns anos de decisões importantes, em que a necessidade de alcançar novamente uma estabilidade financeira fez com que os diretores optassem por começar a produção de livros. Como esse mercado era de gráficas de outros estados, a Empresa A não tinha concorrentes locais. A produção de livros chegou a representar $80 \%$ do faturamento da empresa e a gráfica passou em investir em novos equipamentos de acabamento e impressão de livros. 
A partir de 2004, a produção de livros não se tornou mais interessante, pois várias gráficas da região aderiram à mesma tática e o lucro começou a cair consideravelmente. Em consequência disso foi que a empresa começou a procurar novos mercados e partiu para o atendimento a empresas públicas, de prefeituras e do governo do estado. Hoje, mais de $80 \%$ de sua produção é voltada a esses mercados. Os pedidos são tantos que em certas épocas existe a necessidade de terceirizar alguns impressos com outras gráficas.

Atualmente, porém, a empresa passa por um período em que precisa muito de capital de giro, uma vez que os pagamentos de órgãos públicos são muito demorados. Hoje, a diretoria está avaliando algumas estratégicas, como parcerias com grandes gráficas, para, dessa forma, buscar soluções para a diminuição de custos e o aumento da lucratividade.

\section{Monitoramento de concorrentes na Empresa A}

Os dados da entrevista com o diretor comercial e sócioproprietário da Empresa A mostraram que o grau de preocupação com os concorrentes é baixo. De acordo com o entrevistado, "[...] o que se acompanha sobre concorrentes é em conversas informais, reuniões de sindicatos, em conversas de recepção de clientes [...] os fofoqueiros vendedores dos fornecedores". Esses fornecedores são considerados uma fonte importante de monitoramento, pois falam espontaneamente sobre os concorrentes. A capacidade tecnológica dos concorrentes também é dada pelos fornecedores. Segundo o entrevistado, “[...] esse é o argumento de venda deles [...] existe muita gente que compra se o concorrente comprar".

O entrevistado afirma que procura fazer seu papel como dirigente e deixar o concorrente de lado ou usá-lo como parceiro. De acordo com o entrevistado, “[...] eles mais ajudam do que atrapalham. Tem quinhentas e poucas gráficas no mercado. Nós temos de buscar o nosso espaço, independentemente dos outros. Muitas vezes deixei de ir a reuniões de sindicato para ir a reuniões de política. Não costumo participar de reuniões de sindicato, é analisada a pauta da reunião e se tiver interesse participo, caso contrário não".
A qualidade, porém, é um fator monitorado, pois se sabe quais concorrentes possuem um equipamento moderno, uma vez que é o equipamento que faz com que as gráficas possam alcançar a fatia de mercado de grandes tiragens.

\section{Identificação dos concorrentes}

Os principais concorrentes da Empresa A são três gráficas de grande porte na região, que possuem equipamento semelhante e podem atender o mesmo tipo de cliente. Para se diferenciar desses concorrentes, o entrevistado afirma que o fato de ser o dono e diretor comercial permite uma flexibilidade de negociação e atendimento personalizado que ele mesmo faz, diferentemente das outras empresas, que não rivalizam por se basearem em equipes de representantes comerciais comissionados, o que gera menor rapidez de resposta e de conhecimento técnico.

Tal fato faz diferença quando os clientes estão pressionados pelo tempo e desejam uma oferta de serviço mais imediata. Utilizando a classificação de Bergen e Peteraf (2002), esse grupo pode ser classificado como concorrentes diretos da Empresa A, por compartilhar clientes e dispor de recursos semelhantes.

A Empresa A está entre as maiores da região de Florianópolis, mas existem em torno de 40 ou 50 empresas menores com tamanho aproximado ao seu. Essas empresas atendem clientes empresas privadas e certas agências de publicidade que também são alvo da Empresa A. No entanto, possuem equipamentos que permitem baixas e médias tiragens, embora com qualidade inferior à produzida pela Empresa A. Para com essas empresas, o entrevistado afirma que sempre destaca a garantia da qualidade do serviço que sua empresa oferece, e usa a tradição de serviços prestados nos últimos 40 anos na região. Indagado se esses argumentos surtem efeito nos clientes, o dirigente destaca que para com os clientes mais sensíveis à qualidade, em especial as agências de publicidade, o efeito normalmente é positivo. Utilizando a classificação de Bergen e Peteraf(2002, esse grupo pode ser classificado como concorrentes indiretos da Empresa A por compartilhar clientes, mas não dispor de recursos tecnológicos semelhantes. 
Há também algumas poucas gráficas maiores e com tecnologia mais avançada as quais não são consideradas concorrentes, pois a tecnologia que possuem permite um rápido processamento de alto volume de tiragens que as fazem se concentrar em clientes que não são o foco da Empresa A, que se concentra em médias tiragens para órgãos públicos, agências de publicidade e empresas privadas. Esse grupo de concorrentes não recebe foco de atenção do dirigente da Empresa. O sistema de impressão da Empresa A é conhecido como out-set, no qual a impressora roda 15.000 impressos por hora e o custo é quase o mesmo da impressão de 100 ou 1.000 cópias. Já as grandes gráficas possuem uma máquina de quatro cores e alimentam o papel apenas uma vez na máquina. Nesse tipo de tecnologia digital, o custo é por folha, e a máquina é rotativa e roda 80.000 unidades por hora. Segundo o entrevistado, “[...] enquanto eles levam um dia nós levamos uma semana para fazer uma grande tiragem". A Empresa A possui uma máquina bicolor, em que o papel precisa passar duas vezes na máquina para chegar ao resultado final. Também existe a máquina monocolor, que, de acordo com o entrevistado, a maioria das gráficas utiliza. Esses dados mostram o papel relevante da tecnologia usada pelos concorrentes para a competitividade do setor e para selecionar quem são os concorrentes da empresa sob análise.

Utilizando a classificação de competidores de Bergen e Peteraf (2002), pode-se verificar que a Empresa A se concentra em dois tipos de concorrentes: diretos e indiretos. Concorrentes potenciais não são observados pela Empresa A, que se orienta em primeiro lugar para empresas que atendem os mesmos clientes e em seguida compara os recursos que elas possuem em relação a si. Com esse raciocínio, apenas clientes diretos e indiretos entram no radar de monitoramento e análise. Tal prática deixa de lado concorrentes potenciais, aqueles que possuem recursos semelhantes, mas que atuam com clientes diferentes. A migração ou alteração de clientes por esse grupo pode representar séria ameaça competitiva pelo poder de surpreender a empresa analisada.

\section{Informações sobre os concorrentes}

A Empresa A não possui um elevado grau de preocupação em relação aos seus concorrentes. É usado um software no qual são coletados os custos e divididos por hora máquina. A partir disso é feito o preço final do produto. A margem é sempre a mesma; o cliente pode negociar o preço, mas o concorrente não influencia na tomada de decisão de precificação. O entrevistado salienta que " $[$...] é sempre deixado bem claro que ele pode encontrar um preço menor em função de alguma vantagem que eu vou dar para ele" como a qualidade e a rapidez na entrega do serviço.

Segundo o entrevistado, existem três tipos de clientes: o cliente agência de publicidade, mais exigente, pois conhece o processo e o produto, o cliente governo, que faz pedidos com prazos pré-determinados e, por último, o cliente que quer preço. Quando se trata de analisar uma pequena empresa diante de uma grande, o entrevistado diz que a maioria das pequenas gráficas não possui um sistema de custos, baseando-se em preços dos concorrentes e por isso tem uma vida muito curta.

Assim, os dados sobre os concorrentes que mais são monitorados pela Empresa $\mathrm{A}$ estão ligados a uso de equipamentos e tecnologia. A tecnologia e os equipamentos indicam a capacidade de atender a demanda dos clientes e, consequentemente, de se equiparar com as ofertas da empresa. Também permitem inferir o custo de produção dos concorrentes e identificar aqueles que estão praticando níveis de preços insustentáveis e, portanto, terão de “[...] economizar em algo e vão diminuir a qualidade, mais cedo ou mais tarde". Outros tipos de dados sobre os concorrentes não são buscados com afinco pela Empresa A para situá-los na arena competitiva. Há uma convicção ou filosofia de que se o trabalho for bem feito conquistará clientes; assim, esforços adicionais não se justificariam. $\mathrm{O}$ dirigente entrevistado prefere alocar seu tempo em outras interfaces do ambiente externo, como clientes e contatos em empresas e órgãos governamentais.

\section{Fontes e armazenamento dos dados}

Entre as fontes que melhor informam sobre os concorrentes estão os clientes agências de publicidade em primeiro lugar e em segundo 
lugar os fornecedores. As agências são clientes que possuem as gráficas como seus fornecedores mais comuns e, assim, em seu histórico, acabam mantendo inúmeros contatos e demandando serviços de muitos dos concorrentes da Empresa A. Isso faz com que desenvolvam um conhecimento mais aprofundado de seus fornecedores, sabendo suas falhas, dificuldades, limitações e potencialidades. $\mathrm{O}$ dirigente entrevistado afirma que as agências clientes são as que melhor conhecem as gráficas da região e que "[...] não dá para enganá-las, elas sabem que sabe fazer e o quê", o que as tornam uma importante fonte para se informar sobre os concorrentes.

Os fornecedores da Empresa A, especialmente de equipamentos, são fontes frequentemente acessadas por venderem para os concorrentes e poderem repassar informações sobre quem está investindo e no quê. Como a tecnologia é fator considerado relevante para o mercado de atuação, a Empresa A procura manter contato com fornecedores, mesmo sem ter intenção de comprar novos equipamentos. Apesar de estar em contato com as diversas empresas do setor, os fornecedores são considerados exagerados e infladores de dados, "[...] é preciso dar um desconto em tudo que falam".

As fontes acessadas para informar sobre os concorrentes podem ser classificadas em dos tipos, pessoais e externas à empresa, de acordo com a classificação de Aguilar (1967) e Choo (1999). Fontes do tipo internas ou impessoais escritas não foram identificadas, o que corrobora os estudos sobre monitoramento em pequenas empresas. Smeltzer et al. (1988), Beal (2000) e Haase e Franco (2011) mostram em seus estudos que as pequenas empresas fazem uso intenso de acesso a fontes pessoais informais, como consumidores, fornecedores e competidores, para obter os dados e as informações de que precisam. Em relação ao armazenamento dos dados obtidos dos concorrentes, verificou-se que eles não são armazenados ou registrados, senão na mente do dirigente. Segundo o entrevistado, a informação "[...] é guardada quase que no travesseiro, quando você vai dormir você pensa um pouquinho". Não há uso de arquivos de computadores, repositórios ou pastas que congreguem as informações obtidas. $\mathrm{O}$ entrevistado afirma não ser necessário registrar por escrito, pois "[...] não é tanta coisa assim, dá para lembrar do mais importante".

Indagado se não seria útil agregar essas informações para melhorar o relacionamento e a argumentação com clientes, o entrevistado relatou que foi feita uma pesquisa, encomendada pela Empresa A, para analisar o nível de satisfação dos clientes e a empresa ficou em primeiro lugar, com uma margem de $38 \%$, como a gráfica mais conhecida. Em segundo lugar ficou um competidor que, de acordo com o entrevistado, não é considerado como um concorrente, pois não possui um atendimento à altura, e seus equipamentos estão desatualizados. Dessa forma, avalia que o caminho que vem seguindo é adequado.

\section{CONCLUSÕES}

$\mathrm{O}$ assunto abordado neste projeto tem várias implicações para os administradores em geral e para os profissionais que atuam no campo da informação no contexto organizacional. Em primeiro lugar, os administradores devem reconhecer que o efetivo acompanhamento de tendências e eventos do ambiente pode garantir vantagens competitivas para suas organizações. Eles podem recorrer a serviços externos de informação ou desenvolver e utilizar capacidades internas.

No caso da empresa estudada, verificou-se que a atividade de monitoramento dos concorrentes é pouco valorizada e está centralizada no principal gestor e proprietário, sem participação de outras pessoas. As informações monitoradas dizem respeito a tecnologia e preços, e as principais fontes são informais e externas à empresas, envolvendo alguns clientes e fornecedores. 
O armazenamento e a análise ocorrem pela memória e reflexão pessoal do dirigente, sem compartilhamento com outras pessoas ou com armazenamento das informações obtidas. Os resultados obtidos vão ao encontro de outros estudos acerca de monitoramento ambiental que identificam serem os concorrentes aspectos do ambiente pouco valorizados pelos dirigentes de pequenas empresas.

Em vista dos argumentos apresentados, pode-se empreender que, no âmbito do Brasil, deveriam ser realizados estudos para o conhecimento das diferenças nos estilos e nas estratégias de monitoração entre as empresas que atuam em distintos segmentos econômicos. Foi verificado também que os processos adotados pelas organizações nas atividades de monitoramento ambiental precisam ser melhor compreendidos, principalmente quando se trata de pequenas empresas, pois elas, muitas vezes, negligenciam seu ambiente concorrencial.

É necessário frisar também que cada organização tem suas peculiaridades e deve procurar encontrar a melhor forma de atender suas necessidades de informação externa. A captação dessas informações ambientais não precisa ser feita necessariamente pelos executivos principais de uma organização. Na maioria das vezes, essa tarefa pode ser compartilhada por vários funcionários, o que garante não só maior cobertura do universo informacional, mas também maior envolvimento desses funcionários com os destinos da organização.

A monitoração ambiental é tema de importância não só para pesquisadores, administradores e profissionais da informação, mas também, sob perspectiva mais ampla, para todo um setor econômico. Trata-se de campo complexo e que precisa ser melhor compreendido e administrado. Dessa forma, os administradores devem reconhecer que o efetivo acompanhamento de tendências e eventos do ambiente pode garantir vantagens competitivas para suas organizações.

\section{REFERÊNCIAS}

AGUILAR, F. J. Environmental Scanning. New York: Macmillan, 1967.

ALVES, A. J. O planejamento de pesquisas qualitativas em educação. Cadernos de Pesquisa, São Paulo, v. 77, p. 53-61, maio 1991.

AUSTER, E.; CHOO, C. W. Environmental scanning by CEOS in two Canadian industries. Journal of the American Society for Information Science, vol. 44, n. 4, p. 194-203, 1993.

BABATUNDE, B. O.; ADEBISI, A. O. Strategic environmental scanning and organization performance in a competitive environment. Economic Insights - Trends and Challenges, vol. 64, n. 1, p. 24-34, 2012.

BARBOSA; R. R. Monitoração ambiental: uma visão interdisciplinar. Revista de Administração, São Paulo v. 32, n. 4, p.42-53, outubro/dezembro 1997.

BEAL, Reginald M. Competing effectively: environmental scanning, competitive strategy, and organizational performance in small manufacturing firms. Journal of Small Business Management, v. 38, n. 1, p. $27-47,2000$.

BERGEN, M.; PETERAF, M. Competitor identification and competitor analysis: a broad-based managerial approach. Managerial Decision Economics, vol. 23, p. 157-169, 2002.

BOURGEOIS III, L. J. Strategy and environment: a conceptual integration. Academy of Management Review, v. 5, n. 1, p. 25-39, 1980.

CANCELLIER, É. L. P. L.; ALMEIDA, M. I. R. (2003). Monitoramento Ambiental na Pequena Empresa: uma revisão da literatura. In: KMBRASIL 2003, São Paulo/ SP, Anais... São Paulo: 2003, 1 CD.

CHIZZOTTI, A. Pesquisa em ciências humanas e sociais. 2. ed. São Paulo: Cortez, 1995.

CHOO, C. W. The art of scanning the environment. 
O monitoramento de concorrentes na pequena empresa: um estudo de caso em empresa catarinense

Bulletin of the American Society for Information Science, v. 25, n. 3, p. 21-24, Feb./Mar. 1999.

CHRUSCIEL, D. environmental scan: influence on strategic direction. Journal of Facilities Management, vol. 9, n. 1, p. 7-15, 2011.

DAFT, R. L.; SORMUNEN, J.; PARKS, D. Chief executive scanning, environmental characteristics and company performance: an empirical study. Strategic Management Journal, v. 9, n. 2, Mar./Apr. 1988.

DAFT, R. L.; WEICK K. E. Toward a model of organizations as interpretation systems. Academy of Management Review, v. 9, n. 2, p. 284-295, 1984.

DAVIS, J.A.; MARINO, L. D.; AARON, J. R.; TOLBERT, C. L. An examination of entrepreneurial orientation, environmental scanning, and market strategies of nonprofit and for-profit nursing home administrators. Nonprofit and Voluntary Sector Quarterly, vol. 40, n. 1, p.197-211, 2011.

DILL, W. R. Environment as an influence on managerial autonomy. Administrative Science Quarterly, v. 20, n. 4, p. 613-629, 1958.

DUNCAN, R. B. Characteristics of organizational environments and perceived environmental uncertainties. Administrative Science Quarterly, v. 17, n. 3, p. 313327, Sept. 1972.

FANN, G. L.; SMELTZER, L. R. The Use of Information from and about Competitors in Small Business Management. Entrepreneurship: Theory and Practice; vol. 13, n. 4, 1989.

FRANCO, M.; HAASE, H.; MAGRINHO, A.; SILVA, J. R. Scanning practices and information sources: an empirical study of firm size. Journal of Enterprise Information Management, vol. 24, n. 3, p. 268-287, 2011.

GIL, A. C. Métodos e técnicas de pesquisa social. 4. ed. São Paulo: Atlas, 1994.

GALBRAITH, J. K. A era da incerteza. $7^{\mathrm{a}}$ ed., São
Paulo: Pioneira, 1986

GODOY, A. S. Introdução à pesquisa qualitativa e suas possibilidades. Revista de Administração de Empresas, v. 35, n. 2 , p. $57-63,1995$

GROOM, J. R.; DAVID, F. R. Competitive Intelligence Activity Among Small Firms. S. A. M. Advanced Management Journal, v. 66, n. 1, p. 12-20, 2001.

HARRIS, R. D. Organizational task environments: an evaluation of convergent and discriminant validity. Journal of Management Studies, vol. 41, n. 5, p. 857 $882,2004$.

HAASE, H.; FRANCO, M. Information source for environmental scanning: industry and firma size matter? Management Decision, vol. 49, n. 10, p. 1642-1657, 2011.

KAMOUN-CHOUK, S. Environmental scanning in Tunisian manufacturing SMEs. Journal of Information \& Knowledge Management, vol. 6, n. 1, p. 57-67, 2007.

McEWEN, T. Environmental scanning and organizational performance in entrepreneurial ventures. The Entrepreneurial Executive, vol. 13, p.1-15, 2008.

MENEZES, E. J. C; ALMEIDA, M. I. R. de. Será Possível as Pequenas e Médias Empresas Crescerem sem Informações do Ambiente? Anais do XXI ENANPAD, 1997.

MORGAN, G. Imagens da Organização. São Paulo: ATLAS, 1996.

MUHAMMAD, N. M.; JANTAN, M; TAIB, F. M. Environmental scanning and investment decision quality: information processing quality. Management Research News, vol. 32, n. 12, p. 1117-1129, 2009.

PORTER, M. Vantagem competitiva. Rio de Janeiro: Campus, 1992.

THOMPSON, J. D. Dinâmica organizacional. São Paulo: McGraw-Hill do Brasil, 1976. 
SMELTZER, L. R.; FANN, G. L.; NIKOLAISEN, V. $\mathrm{N}$. Environmental scanning practices in small business. Journal of Small Business Management, vol. 26, n. 3, p. 55-62, 1988.

STEWART, W. H.L; MAY, R. C.; KALIA, A. Environmental perceptions and scanning in the United States and India: convergence in entrepreneurial information seeking? Entrepreneurship: Theory and Practice, vol. 32, n. 1, p. 83-106, 2008.

TRIVIÑOS, A. N. S. Introdução à pesquisa em ciências sociais. São Paulo: Atlas, 1987.

TUSHMAN, M., NADLER, D. Organizando-se para a Inovação. In: STARKEY, K. Como as organizações aprendem. São Paulo: Futura, 1997.

WALTERS, B. A.; JIANG, J. J.; KLEIN, G. Strategic information and strategic decision making: the EIS/ CEO interface in smaller manufacturing companies. Information \& Management, vol. 40, n. p. 487-495, 2003 .

WEICK, K. E. A psicologia social da organização. São Paulo: E. Blucher/EDUSP, 1973.

YIN, R. K. Estudo de caso: planejamento e métodos. 2. ed.. Porto Alegre: Bookman, 2001.

ZHANG, X.; MAJID, S.; FOO, S. Environmental scanning: an application of information literacy skills at the workplace. Journal of Information Science, vol. 36, n. 2, p. 719-732, 2010. 